\title{
MPEG-7 low level image descriptors for modeling users' web pages visual appeal opinion
}

\author{
Silvia Uribe, Federico Álvarez, Member IEEE, José Manuel Menéndez, Member IEEE
}

\begin{abstract}
The study of the users' web pages first impression is an important factor for interface designers, due to its influence over the final opinion about a site. In this regard, the analysis of web aesthetics can be considered as an interesting tool for evaluating this early impression, and the use of low level image descriptors for modeling it in an objective way represents an innovative research field. According to this, in this paper we present a new model for website aesthetics evaluation and users' opinion prediction based on the use of some parameters derived from the MPEG-7 standard, which are related to three different dimensions of the image: texture, chrominance and luminance. The obtained results confirms the power of our solution, as well as the usefulness of the model for reducing costs during the design and implementation process of new websites by providing a rapid feedback about the interface visual appeal.
\end{abstract}

Index Terms - web aestheties, first opinion, image descriptor, regression model.

\section{INTRODUCTION}

The influence of interactive systems' aesthetics has been increased since its first definition, becoming a critical factor for assuring users' acceptance [1]. Therefore, it is vital that developers design for aesthetics since the earliest stages of the creation process, which brings a new discipline called 'engineering aesthetics' [2].

Some previous works are focused on inferring users' preferences by analyzing different visual elements, like complexity, balance or equilibrium of the content contained in the websites [3]. Nevertheless, due to the rapidness of the users' first opinion generation (over $50 \mathrm{~ms}$ [4]), other rudimentary elements from the human visual system must be considered above the previous ones [5]. For this reason, features like luminance, color and texture of the interface seems to be more important and earlier perceived than other complex elements. And, in this regard, the MPEG-7 standard [6] defines a set of descriptors for visual media that can be helpful.

The analysis of the previous features may help the developers to improve the solution by obtaining important feedback since the early stages of the website development, which may provide a reduction of the engineering costs in terms of time and money.

Following these ideas, in this paper we present an innovative evaluation model composed by 10 low level descriptors, derived from the MPEG-7 standard, which does not take into account any other information about the content and context of use, in order to obtain objective and fast evaluation information. So the main contributions of our work can be summed up as follows:

- We identify a set of 15 low level image descriptors, derived from MPEG-7, to analyze website aesthetics.

- The prediction model obtained is based on 10 of these new parameters.

- Our model provides a higher accuracy level to the users' opinion with a shorter set of elements than previous works.

- Thanks to that, this model may help the developers to obtain relevant objective feedback about the website appeal, which may reduce the costs by assuring users' acceptance.

The reminder of this paper is organized as follows: Section II presents an overview of related work in web aesthetic evaluation. Then, Section III presents our model with the obtained results and a comparative analysis with previous research works in order to identify the strength of our model. Finally, some implications are discussed and some possible future lines to evolve the model are presented.

\section{RELATED WORK}

Along the human history, aesthetics has been the center of numerous studies in areas such as philosophy, science and arts. These previous studies can be considered the starting point for the assessment of the attractiveness in the Human Computer Interaction ( $\mathrm{HCI}$ ) field, where the term 'aesthetics' is sometimes replaced by other concepts, like 'beauty', 'visual appeal', and 'pleasure'. In this regard, its meaning was specifically described by [7], where the authors considered website aesthetics "as the immediate pleasurable subjective experience that is directed toward an object and not mediated by intervening reasoning'. 
Although studies in HCI have been usually focused on the analysis of efficiency and effectiveness of interactions (typical dimensions of usability as it is explained in [8] and [9]), recent efforts are more interested in the evaluation of other components of the general experiential perspective such as aesthetics. The beginning of this new line of research can be dated to the work by [10], who defined an association between visual appeal and subjective assessment of usability based on the extension of some previous works ([11] and [12]), and whose main conclusion was the statement that beautiful designs are usable.

According to the relevance of these kind of studies, in this paper we focus on objective methods for web aesthetic evaluation, due to the fact that they provide a faster and more efficient evaluating method in terms of cost and time than subjective analysis. Nevertheless, the relationship between both evaluation methods has been previously studied [13], even in usability research field [14].

In this respect, some previous research works have focused on this area. In [3] and [15], the authors define different sets of parameters to evaluate the complexity of a web, but these studies do not provide a final model for evaluating aesthetics, and they depends of a screen division which is not an standardized process. In [16] the authors provide another simple method for assessing aesthetics considering the content elements of the web, but they do not take into account the color analysis. Finally, [17] provides a full model for complexity and colorfulness evaluation, but it represents a complex and time-consuming solution due to the number of considered parameters.

Having in mind the current state in this area, and in order to provide an efficient and automated novel algorithm for web aesthetic evaluation, in this paper we provide an entire evaluation method composed by objective parameters, based on MPEG-7 descriptors, for predicting users' opinion about website visual appeal.

\section{A NEW LOW LEVEL MODEL FOR WEBSITE AESTHETICS BASED ON MPEG-7 DESCRIPTORS}

\section{A. Low level descriptors}

Our model is strictly based on the analysis of the low level image characteristics of the website screenshots [18]. To do so, we make use of a set of parameters derived from the MPEG-7 standard, which are related to three main dimensions of the image: luminance, texture and color, as some of the most important properties for the visual psychobiological process ([19], [20]):

\section{1) Luminance descriptors:}

- Direct luminance $\left(\mathrm{L}_{\mathrm{m}}, \mathrm{L}_{\mathrm{v}}\right)$ : determines the image mean and variance saturation in order to distinguish between brightness and darkness interfaces.

- $\quad$ Bit plane distribution entropy (E1, E2, E3, E4): it is in charge of analyzing the entropy distribution across the four highest bit planes of the image.

2) Texture descriptors:
- $\quad$ Line energy (LE): it measures the total line density in the image.

- Line homogeneity (LH): in charge of providing the image line continuity.

- Entropy variety $\left(\mathrm{E}_{\mathrm{V}) \text { : }}\right.$ it measures the entropy variance of the image.

3) Color descriptors:

- Chromatic variety $\left(\mathrm{N}, \mathrm{VC}_{\mathrm{intra}}, \mathrm{VC}_{\text {inter }}\right)$ : it is in charge of providing the number of dominant colors, and the variances between same tonalities and between different colors.

- $\quad$ Spatial coherence (SC): its main purpose is to measure the continuity of the color in the image.

- HSV color space $\left(S_{m}, S_{v}\right)$ : this parameter is in charge of providing the mean and the variance values of the saturation in the image, in order to detect their impact in the users' assessments.

\section{B. Obtained model}

Once we have established the low level descriptors to be used, the next step is the definition of the model. To do so, we obtain our model by characterizing the website through lowlevel descriptors and their associated users' visual appeal opinion (in a Likert scale, from 1 to 9), available on a public database with 450 websites provided by the authors in [21]. To that end, we apply a stepwise multiple linear regression algorithm [22], which combines the forward and backward selection techniques to take advance of both methods by selecting only the descriptors which are statistical significant for the model.

In order to avoid overfitting problems in the regression model extraction, we also apply a $k$-fold cross validation process, where we define $k$ as 5 due to the size of the dataset. With this technique, we divide the entire dataset into 5 complementary subsets, and then we perform the regression process to the training set (composed by the merging of 4 different subsets) and the validation to the remaining subset. We repeat the process until all the subsets have been used as validation sets. Once this is done, we select the model that provides more accurate results for each test subset and then we apply it to the entire dataset.

Table 1 shows the obtained regression model parameters for the normalized information in the dataset, according to the above explained process.

Table 1 Regression model for MPEG-7 based low level parameters

\begin{tabular}{|c|c|c|c|}
\hline Parameter & Estimate & SE & pValue \\
\hline Constant & 0.202 & 0.081 & 0.013 \\
\hline $\mathrm{LE}$ & -0.182 & 0.091 & 0.046 \\
\hline $\mathrm{L}_{\mathrm{m}}$ & 0.012 & 0.057 & 0.823 \\
\hline $\mathrm{E} 1$ & 0.269 & 0.087 & 0.002 \\
\hline $\mathrm{E} 2$ & 0.192 & 0.079 & 0.015 \\
\hline $\mathrm{E} 3$ & 0.222 & 0.062 & $4.56 \mathrm{e}-04$ \\
\hline $\mathrm{N}$ & -0.005 & 0.086 & 0.947 \\
\hline $\mathrm{VC}_{\text {intra }}$ & 0.343 & 0.120 & 0.004 \\
\hline
\end{tabular}




\begin{tabular}{|c|c|c|c|}
\hline $\mathrm{VC}_{\text {inter }}$ & -0.600 & 0.073 & $1.11 \mathrm{e}-14$ \\
\hline $\mathrm{SC}$ & 0.674 & 0.133 & $7.96 \mathrm{e}-07$ \\
\hline $\mathrm{S}_{\mathrm{v}}$ & -0.020 & 0.066 & 0.760 \\
\hline $\mathrm{LE}: \mathrm{N}$ & -0.294 & 0.058 & $9.605 \mathrm{e}-07$ \\
\hline $\mathrm{LE}: \mathrm{S}_{\mathrm{v}}$ & 0.253 & 0.079 & 0.001 \\
\hline $\mathrm{E} 1: \mathrm{E} 2$ & 0.147 & 0.073 & 0.046 \\
\hline $\mathrm{E} 1: \mathrm{SC}$ & -0.208 & 0.075 & 0.006 \\
\hline $\mathrm{E} 2: \mathrm{S}_{\mathrm{v}}$ & -0.214 & 0.053 & $8.75 \mathrm{e}-05$ \\
\hline $\mathrm{VC}_{\text {inter }}: \mathrm{SC}$ & 0.348 & 0.055 & $9.89 \mathrm{e}-10$ \\
\hline $\mathrm{L}_{\mathrm{m}} \wedge$ & -0.164 & 0.052 & 0.002 \\
\hline $\mathrm{Num}$. of observations:332 & RMSE: 0.79 & $\mathrm{R}^{2}: 0.404$ \\
\hline $\mathrm{R}^{2} \mathrm{adj}: 0.37$ & F stat.:12.5 & $\mathrm{p}$-value: $1.47 \mathrm{e}-26$ \\
\hline
\end{tabular}

According to the model definition, we can establish that the most influential coefficients are the ones related to the color continuity (SC) and the variability between different colors $\left(\mathrm{VC}_{\text {inter }}\right)$, which gives an idea of the color complexity of the web. This fact supports the idea of the relevance of color information in websites for users' evaluation, as some previous research works have pointed out [23].

Moreover, based on the obtained results, our model is able to explain the $40.4 \%$ of the variability of the data with a 0.79 of RMSE, which improves some previous research work by making use of a smaller set of parameters [21] (without taking into account the demographic information for model adaptation to each user). In particular, the next table shows a comparison for these two models:

\section{Table 2 Comparison table for both models}

\begin{tabular}{|c|c|c|}
\hline Parameter & Reinecke's Model & Our Model \\
\hline RMSE & 0.861 & 0.79 \\
\hline $\mathrm{R}^{2}$ & 0.267 & 0.404 \\
\hline $\mathrm{R}^{2}$ adj. & 0.254 & 0.332 \\
\hline $\mathrm{pValue}$ & $1.15 \mathrm{e}-19$ & $1.47 \mathrm{e}-36$ \\
\hline $\begin{array}{c}\text { number of descriptors } \\
\text { in the model }\end{array}$ & 17 & 10 \\
\hline
\end{tabular}

As it is shown above, our model presents a more accurate solution in terms of RMSE, improving the explanation of the variability of the analyzing ratings in a $51 \%$ with a smaller set of parameters. This means that our model provides a simpler way to predict web aesthetic assessment with more precise results.

\section{Model validation}

Once we have obtained the regression model for the web aesthetic evaluation, the next step to be undertaken is the validation over a different dataset. For this purpose we have used two different datasets:

- The generic dataset provided in [24], which is composed of the assessment information of 41 webs by 512 users, with a 1-7 Likert scale.

- A new dataset composed by the evaluation of 6 different search engines websites from 120 users in order to particularize to a specific scenario (with a 1-10 Likert scale).
The first dataset provides the assessment information by considering two main dimensions of the aesthetic in HCI design: classic aesthetic, which is related to the orderly and clear design, and expressive aesthetic, which is more related to the artistic sense of the web, that is, to its creativity and originality. According to this, the next table presents the obtained results (we provide the obtained RMSE in absolute and relative terms according to the used scale).

\section{Table 3 Validation results of the model with a generic dataset}

\begin{tabular}{|c|c|c|}
\hline & Classic aesthetic & Expressive aesthetic \\
\hline RMSE & $1.336(19.1 \%)$ & $1.154(16.5 \%)$ \\
\hline
\end{tabular}

As may be seen in Table 3, our model presents a higher accuracy for the expressive aesthetics level. This may be related to the fact that our model assesses the web composition in terms of low level parameters, which are directly related to the image perception process, but we are not taking into account the common parameters to evaluate aesthetics in terms of complexity descriptors (balance, symmetry, unity, etc.), more related to the classic dimension.

Finally, the users' opinions for the second dataset have been also obtained by means of considering different dimensions of the web aesthetic: the level of the diversity, the care in the design and finally the perceived aesthetic level of the web. According to this, the obtained results are provided in Table 4:

\section{Table 4 Validation results of the model with a specific dataset}

\begin{tabular}{|c|c|c|c|}
\hline & $\begin{array}{c}\text { Designed } \\
\text { with care }\end{array}$ & $\begin{array}{c}\text { Varied } \\
\text { design }\end{array}$ & $\begin{array}{c}\text { Aesthetic level } \\
\text { (general score) }\end{array}$ \\
\hline RMSE & $2.88(28.8 \%)$ & $2.98(29.8 \%)$ & $1.49(14.9 \%)$ \\
\hline
\end{tabular}

In this case, our model provides more accurate results for the aesthetic level prediction than to the other features of the design. This may be related to the fact that users do not consider variety and care in the design as relevant features in the aesthetics of a search engine website.

\section{CONCLUSIONS, LimitATION AND FUTURE WORK}

According to the aim of this paper, we have defined a new model for an objective aesthetics evaluation of web pages based on the use of 10 low level descriptors derived form the MPEG-7 standard. These parameters assess three main dimensions of the human visual perception (luminance, chrominance and texture), and their importance for the website visual appeal evaluation by the users is proved due to the obtained results.

These results also confirm a high prediction accuracy with a small set of parameters and without considering website content. Besides, we can also confirm our initial idea that relates rapid users' evaluation with low level features above other interface aspects, such as the content information. 
Moreover, one additional clear strength of the current approach compared to others is that it provides an entire automated solution, without containing any subjective stage in the analysis process.

Based on these reasons, the practical implications of our work can be summarized with the following three main ideas:

- The definition of a set of 10 low level parameters based on MPEG-7 to characterize website aesthetics, according to the most important factors for the human perception process: texture, luminance and chrominance.

- The design of a new model for predicting users' first impression about website appeal based on these parameters.

- The analysis of the model results over different dimensions of the website appeal (classic vs. expressive aesthetics), have provided a higher accuracy with the artistic aspect of the design.

In this regard, this model can serve as a foundation for an objective tool that provides quantitative information about the visual appeal in the design process. This tool may reduce the development time, which may improve the implementation process in time and costs terms.

Nevertheless, this model can be evolved to achieve a more personal prediction solution. In this way, the main important future research line can be related to the consideration of the influence of users' demographics and background in their perception. By doing so, our model may become an innovative tool for the automatic adaptation of websites layouts, helping the developers to obtain an interface that can be easily accepted by each user.

\section{ACKNOWLEDGMENT}

The authors would like to thank Dr. Katharina Reinecke of University of Michigan and Krysztof Z. Gajos of Harvard University for contributing the first public dataset on website visual appeal. This publication has been partially funded by the HORFI project (TEC2012-38402-C04-01).

\section{REFERENCES}

[1] Mahlke, S. Factors influencing the experience of website usage. In CHI '02 Extended Abstracts on Human Factors in Computing Systems. ACM, New York, NY, USA, pp. 846847. 2008.

[2] Liu, Y. Engineering aesthetics and aesthetic ergonomics: Theoretical foundations and a dual-process research methodology. Ergonomics, vol. 46, 13-14, pp. 1273-1292. 2003.

[3] Ngo, L, Samsudin, A., Abdullah, R. 2000. Aesthetics measures for assessing graphic screens. J. of Information Science and Engineering, 16, 1 (2000), 97-116.

[4] Lindgaard, G., Fernandes, G., Dudek, C., Brown, J.M. Attention web designers: You have 50 milliseconds to make a good first impression!. Behaviour \& Information Technology vol. 25, 2, pp. 115-126. 2000.

[5] Hubel, D.H. and Wiesel, T.N. Brain mechanism of vision. Scientific American vol. 241, 3, pp. 150-162. 1979.
[6] Salembier, P., Sikora, T. Introduction to Mpeg-7: Multimedia Content Description Interface. B.S. Manjunath (Ed.). John Wiley \& Sons, Inc., New York, NY, USA. 2002.

[7] Moshagen, M. and Thielsch, M. T. 2010. Facets of visual aesthetics. Int. J. Hum.-Comput. Stud. 68, 10 (October 2010), 689-709. DOI://dx.doi.org/10.1016/j.jjhcs.2010.05.006

[8] Nielsen, J. 1993. Usability Engineering. Morgan Kaufmann Publishers Inc., San Francisco, CA, USA.

[9] Shackel, B. 2009. Usability - Context, framework, definition, design and evaluation. Interact. Comput. 21, 5-6 (December 2009), 339-346. DOI= http://dx.doi.org/10.1016/j.intcom.2009.04.007

[10] Tractinsky, N., Katz, A. S., Ikar, D. 2000. What is beautiful is usable. Interacting with computers, 13, 2 (December 2000), 127145, DOI: http//dx.doi.rog/10.1016/S0953-5438(00)00031-X

[11] Kurosu, M. and Kashimura, K. 1995. Apparent usability vs. inherent usability: experimental analysis on the determinants of the apparent usability. In Conference Companion on Human Factors in Computing Systems (CHI 95), I. Katz, R. Mack, and L. Marks (Eds.). ACM, New York, NY, USA, 292-293. DOI=http:/doi.acm.org/10.1145/223355.223680.

[12] Tractinsky, N. 1997. Aesthetics and apparent usability: empirically assessing cultural and methodological issues. In Proceedings of the ACM SIGCHI Conference on Human factors in computing systems (CHI 97). ACM, New York, NY, USA, 115-122. DOI=http $/ /$ doi.acm.org $/ 10.1145 / 258549.258626$

[13] Altaboli, A and Lin, Y. 2011. Objective and subjective measures of visual aesthetics of website interface design: the two sides of the coin. In Proceedings of the 14th international conference on Human-computer interaction: design and development approaches - Volume Part I (HCII'11), Julie A. Jacko (Ed.), Vol. Part I. Springer-Verlag, Berlin, Heidelberg, $35-44$.

[14] Donyaee, M., Seffah, A., Rilling, J.. 2006. Exploring the correlations between predictive usability measures and user test. International Conference on Software and Product Measurement (MENSURA). (2006).

[15] Fu, F., Chiu, S. Y., and Hung Su, C.. 2007. Measuring the screen complexity of web pages. In Proceedings of the 2007 conference on Human interface: Part II, Michael J. Smith and Gavriel Salvendy (Eds.). Springer-Verlag, Berlin, Heidelberg, 720-729.

[16] Nebeling, M., Matulic, F., and Norrie, M. C. 2011. Metrics for the evaluation of news site content layout in large-screen contexts. In Proceedings of the SIGCHI Conference on Human Factors in Computing Systems (CHI '11). ACM, New York, NY, USA, 1511-1520. DOI= http://doi.acm.org/10.1145/1978942.1979164

[17] Reinecke, K., Yeh, T., Miratrix, L., Mardiko, R., Zhao, Y., Liu, J., and Gajos, K. Z. 2013. Predicting users' first impressions of website aesthetics with a quantification of perceived visual complexity and colorfulness. In Proceedings of the SIGCHI Conference on Human Factors in Computing Systems (CHI '13). ACM, New York, NY, USA, 2049-2058. DOI= http://dx.doi.org 10.1145/2470654.2481281

[18] Sánchez, F., Barrilero, M., Uribe, S., Álvarez, F., Tena, A. and Menéndez, J.M. Social and Content Hybrid image Recommender System for Mobile Social Networks", Mobile Networks and Applications, vol 17,6, pp. 782-795. 2012

[19] Palmer SE, Rock I. Rethinking perceptual organization: The role of uniform connectedness. Psychonomic Bulletin \& Review. 1994:1:29-55. 
[20] Gilchrist ID, Humphreys GW, Riddoch MJ, Neumann H. Luminance and edge information in grouping: A study using visual search. Journal of Experimental Psychology: Human Perception and Performance. 1997;23:464-480.

[21] Reinecke, K. and Gajos, K.Z. Quantifying visual preferences around the world. In Proceedings of the SIGCHI Conference on Human Factors in Computing Systems (CHI '14). ACM, New York, NY, USA, pp. 11-20. 2014
[22] Hintze, J. L.. 2007. Stepwise regression. On NCSS Statistical System User's Guide III Regression and Curve Fitting. Chapter 311. 197-207 (2007).

[23] Cyr, D., Head, M., and Larios, H. Colour appeal in website design within and across cultures: A multi-method evaluation. Int. J. Hum.-Comput. Stud. vol 68, 1-2, pp. 1-21, January 2010.

[24] Thielsch, M. T, and Hirschfeld, G. 2012. Spatial frequencies in aesthetic website evaluations- explaining how ultra rapid evaluations are formed. Ergonomics, 55 (7), (2012), 731-742. $\mathrm{DOI}=10.1080 / 00140139.2012 .665496$. 